$\xi=-1$

\title{
A novel petri nets algorithm using conditional probability for the evaluation of composite power system reliability
}

\author{
T. Bharath Kumar ${ }^{1}$, B. Hema Bhargavi ${ }^{1}$, A. Chinmai ${ }^{1}$ \\ ${ }^{1}$ Koneru Lakshmaiah Educational Foundation, Vaddeswaram, Guntur (District), A.P, INDIA \\ *Corresponding author E-mail: drbharath@kluniversity.in
}

\begin{abstract}
Reliability of an electrical power system plays a vital role in providing continuous power supply to consumers with greater quality. The power demand is increasing day by day due to the increased population, modern society and are seeking highly reliable power. The assessment of reliability is very difficult due to the presence of large number of components and complex power system network configurations. This paper address a novel useful step by step algorithm for the assessment of average power availability at load buses us-ing the concept of modified Petri nets with conditional probability. The proposed algorithm is very efficient and can applicable to any number of the bus system. The proposed algorithm is tested with Roy Billiton practical example, IEEE 6 bus, IEEE 14 bus and IEEE RTS-96 bus system. The obtained results are validated by Monte Carlo simulation method, Classical Node elimination method and mod-ified minimal cut set method.
\end{abstract}

Keywords: Conditional Probability; Failure Rate; Monte Carlo Simulation; Repair Rate; Series-Parallel Equivalence; Star Delta Conversion.

\section{Introduction}

The electric power system is one of the most important and highly complex system, it is an ocean of connections with various components and elements like generators, transformers, circuit breakers, relays, and transmission lines etc., which are recognized by the mankind. Owing to the difficulty of the electric power systems and difficult to define and judge the level of reliability in an interconnected power system. Moderately, several tools, methodologies and measurements are developed to overcome the issues about the power system reliability each from its point of view [1][4]. The power system reliability is mainly divided into security and adequacy. The security is correlated to the capacity of the electric power system to respond to transients and disturbances that occur in the system. The adequacy is correlated to the existence of enough generation of the electric power system to satisfy the customer demand in static terms. The composite power system reliability this includes generation and transmission and it is very much need to the power system planners. In this power generation and planning, a number of new approaches and techniques were developed to reduce the conflicts between the economic and reliability constraints [5].

Power system reliability is commonly measured in terms of "average power availability". The improvement in the power availability is needed in order to meet the requirements of the consumer demand. The power engineers must know the level of reliability and the methodologies to calculate the average power availability in a complex power network. The power availability of any system is achieved by tracing the number of available paths in the overall system [6]-[10]. This is how the evaluation of Petri nets concept comes into the picture. The main data required for the evaluation of the reliability of generation system are the failure rate and repair rates. On knowing the failure rate and repair rate we can determine the availability and unavailability of any system.
In case of transmission system because of increased demand, it is operated under heavily loaded conditions, due to this the system becomes unstable which tends to loss in power availability. Recent surveys shows that most of the system failures took place due to the overloaded conditions, where there is a need for efficient and reliable methods to measure the reliability level of the present power system. The Monte Carlo simulation is a well-known method in power availability calculation and it takes large time for the generation of uniformly distributed random number and further calculations. The series-parallel equivalences in power availability calculations, there will be complexity in the identification of such structures in power system networks (star-delta, delta-star) [11]-[21]. Where as in the proposed method representing an algorithm for obtaining the power availability. This is based on the conditional probability approach reduces the complexity of determining the power availability. To overcome the limitations and drawbacks that are prevailed while dealing the power availability assessment using Monte Carlo simulation, series-parallel and star/delta equivalence.

The Petri nets have been widely used in system reliability evaluation, fault-tree analysis, distributed databases and other applications. In this area of power system reliability evaluation, Petri nets have been used to determine simple tie sets, identification of $\mathrm{k}$ trees and in analyzing fault tree analysis. This Petri nets concept deals with the available paths in the system and the power flow from one bus to another bus. It is necessary to find the transitions of the given graph by which a token at a destination node is reachable from a token at a source place. Therefore, a Petri net concept is an approach which deals with the tracing of power flow paths from where we can estimate the power availability. In this method, we assume that there will be $100 \%$ reliability at generating unit and to calculate the average power availability of each load. This method takes less computation time and makes the network simple in nature when compared to the previous methods. In this method, if the stress level of any bus is more or it exceeds the acceptable 
limits of active power, reactive power, voltage and load angle then addition of new paths is taken place with the help of proposed algorithm with conditional probability. In the traditional Petri net method, an assumption of the probability of average power availability at the receiving end is considered as probability of 1 , which is practically not possible. Knowing the probabilities of power availability at generators, the probability of power availability at all loads can be computed. But in practical applications, 100\% reliability is not possible at receiving end of any power system. This assumption in the traditional Petri net method overcome by the proposed algorithm. The proposed algorithm uses modified Petri net method on application of conditional probability which is explained clearly in the appendix.

The proposed algorithm has all the following advantages over the traditional methods like tracing of power flow paths, seriesparallel equivalence, star-delta conversion and Monte Carlo simulation methods.

1) Less complexity and less computational time.

2) Program developing is easy.

3) Can applicable to $\mathrm{N}$ number of bus system for the analysis of reliability.

4) Power availability can be calculated even by extending the actual bus system.

The following sections describes the Evolution Technique, Results and decisions, and finally conclusion.

\section{Evaluation technique}

The steps involved in the proposed algorithm are:

1) Collect the input data which includes the reliability data like repair rate, failure rate etc., of each component.

2) Identification of input and output nodes has to be done.

3) Draw the directed graph from the overall network.

4) Identify the Cut sets which isolates the loads.

5) Representation of reliability parameters (repair rate, failure rate) of all the branches has to be done.

6) A particular load bus has been chosen for which the power availability is to be evaluated.

7) If the parameters of the obtained bus and the generator bus are same then a new branch has to be created or else the repeat the procedure.

8) Representation of equivalent parameters of each independent paths by using the conditional probability.

9) Calculation of power availability should be done with the obtained parameters using Petri nets.

10) Repeat the steps for all the individual loads with their reliability parameters.

The proposed algorithm is applied for a practical example taken from Roy Billiton paper and is shown Fig.1. The system is interconnected with various elements like transformers, generators and failure, repair rates are assumed to be same for the whole system.

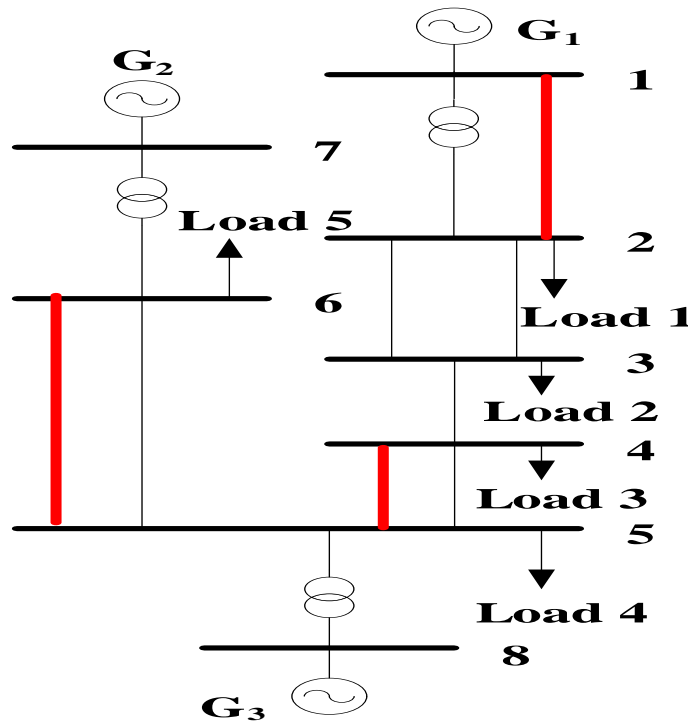

Fig. 1: Practical Example.

\section{Results and discussions}

The proposed algorithm which was presented in the previous section has been applied to a practical example. The reliability data is assumed to be identical for all the components $(\lambda=0.1, \mu=10)$. The proposed method is validated with the results that are obtained by the Monte Carlo simulation and Series-Parallel equivalence. The Petri nets algorithm generates the tokens and gave some additional branches to increase the average power availability at different load buses and are marked as red lines in the diagram. The proposed method is also applied for IEEE 6 bus system shown in fig. 2 . The reliability data of the system is given in the appendix. The power availability at the load buses is in table 2 .

Table 1: Average Power Availability in A Practical Example

\begin{tabular}{lllll} 
S. & Load & $\begin{array}{l}\text { Proposed } \\
\text { Nethod }\end{array}$ & $\begin{array}{l}\text { Monte Carlo } \\
\text { Simulation method }\end{array}$ & $\begin{array}{l}\text { Node Elimina- } \\
\text { tion Method }\end{array}$ \\
\hline 1 & Load-1 & 0.994 & 0.989 & 0.994 \\
2 & Load-2 & 0.982 & 0.974 & 0.982 \\
3 & Load-3 & 0.981 & 0.956 & 0.981 \\
4 & Load-4 & 0.990 & 0.985 & 0.990 \\
5 & Load-5 & 0.981 & 0.965 & 0.981 \\
\hline
\end{tabular}

The difficulty in the identification of the power flow paths is overcome by the modified Petri Nets algorithm and the classical node elimination method. The general assumption of probability of power availability at receiving end is eliminated by applying the concept of conditional probability.

Table 2: Average Power Availability for IEEE 6 Bus System

\begin{tabular}{lllll}
\hline S. No & Load No & $\begin{array}{l}\text { Proposed } \\
\text { Method }\end{array}$ & $\begin{array}{l}\text { Monte Carlo } \\
\text { Simulation } \\
\text { method }\end{array}$ & $\begin{array}{l}\text { Node Elim- } \\
\text { ination } \\
\text { Method }\end{array}$ \\
\hline 1 & Load-1 & 0.991 & 0.92737 & 0.991 \\
2 & Load-2 & 0.982 & 0.89847 & 0.982 \\
3 & Load-3 & 0.930 & 0.90790 & 0.930 \\
4 & Load-4 & 0.882 & 0.85934 & 0.882 \\
5 & Load-5 & 0.881 & 0.8841 & 0.881 \\
\hline
\end{tabular}




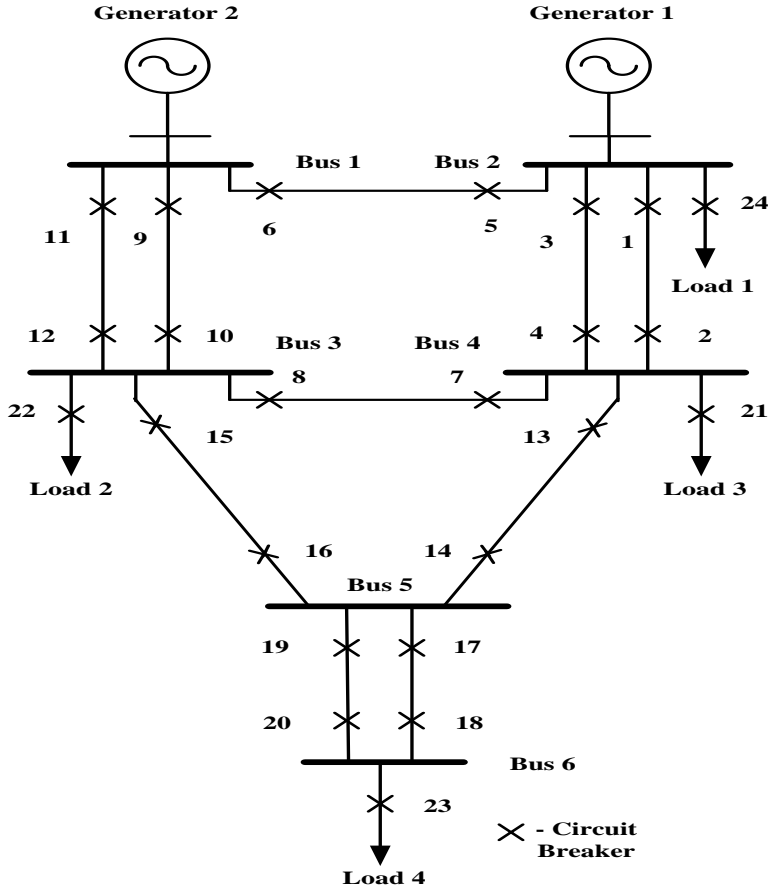

Fig. 2: IEEE 6 Bus Reliability Test System.

To evaluate the availability in an efficient manner the proposed method is also applied to IEEE 14 bus system and IEEE RTS 96 system. These are shown in fig. 3 and fig. 4 respectively and the reliability data is given in the appendix.

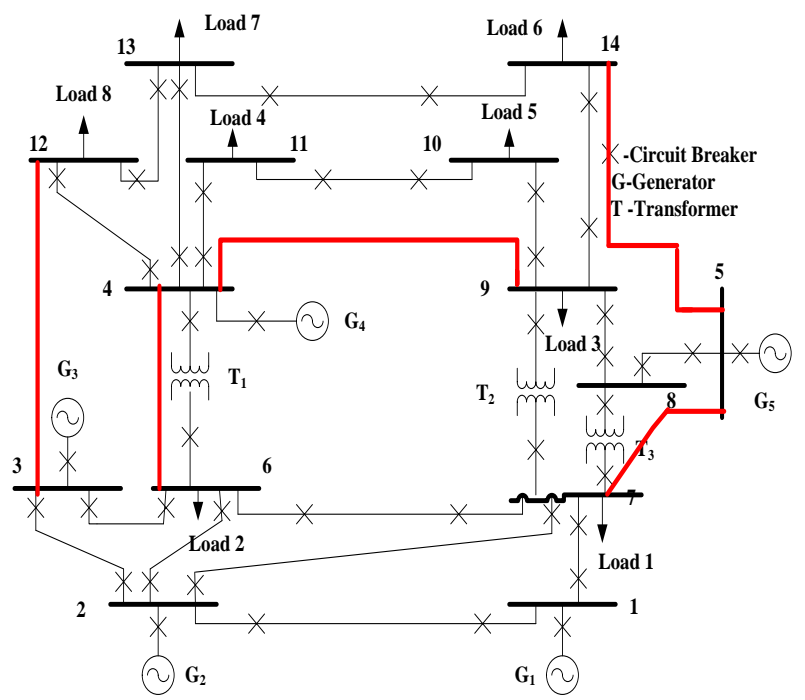

Fig. 3: IEEE 14 Bus Reliability Test System.

Table 3: Average Power Availability at Different Loads in14 Bus System

\begin{tabular}{|c|c|c|c|c|}
\hline $\begin{array}{l}\text { S. } \\
\text { No }\end{array}$ & $\begin{array}{l}\text { Load } \\
\text { No }\end{array}$ & $\begin{array}{l}\text { Proposed } \\
\text { Method }\end{array}$ & $\begin{array}{l}\text { Monte Carlo } \\
\text { Simulation method }\end{array}$ & $\begin{array}{l}\text { Node Elimina- } \\
\text { tion Method }\end{array}$ \\
\hline 1 & Load-1 & 0.952 & 0.941 & 0.952 \\
\hline 2 & Load-2 & 0.951 & 0.948 & 0.951 \\
\hline 3 & Load-3 & 0.964 & 0.954 & 0.964 \\
\hline 4 & Load-4 & 0.921 & 0.921 & 0.921 \\
\hline 5 & Load-5 & 0.910 & 0.910 & 0.910 \\
\hline 6 & Load-6 & 0.911 & 0.910 & 0.911 \\
\hline 7 & Load-7 & 0.942 & 0.933 & 0.942 \\
\hline 8 & Load-8 & 0.933 & 0.921 & 0.933 \\
\hline
\end{tabular}

The performance of the proposed algorithm is tested with IEEE RTS 96 single area reliability test system and results are compared with the Node Elimination method.

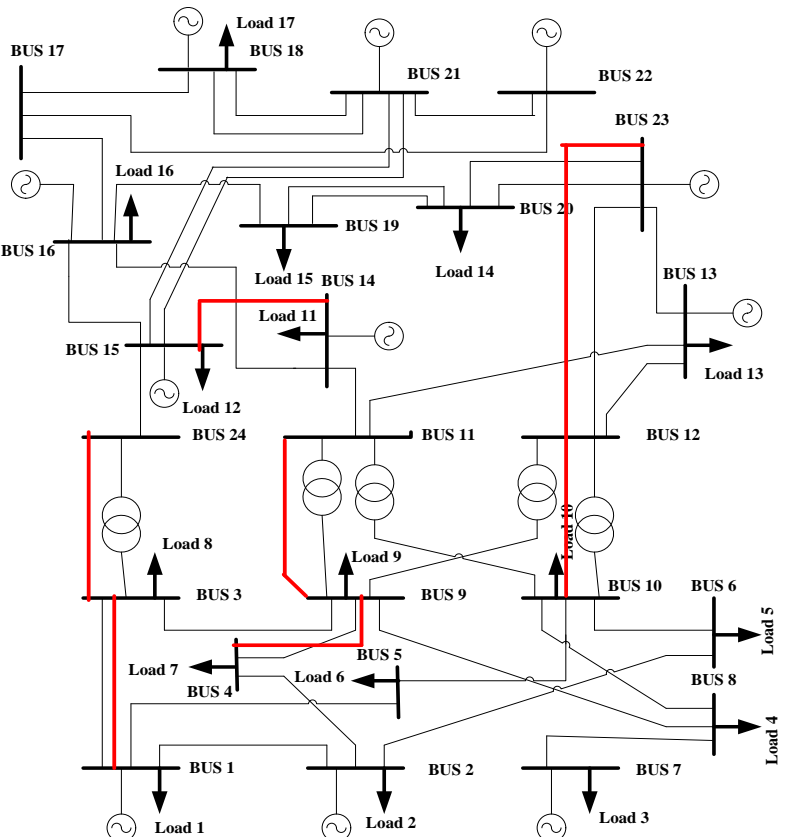

Fig. 4: IEEE RTS 96 Bus System.

Table 3: Average Power Availability at Different Loads in 14 Bus System

\begin{tabular}{|c|c|c|c|c|}
\hline $\begin{array}{l}\text { S. } \\
\text { No }\end{array}$ & $\begin{array}{l}\text { Load } \\
\text { No }\end{array}$ & $\begin{array}{l}\text { Proposed } \\
\text { Method }\end{array}$ & $\begin{array}{l}\text { Monte Carlo Simu- } \\
\text { lation method }\end{array}$ & $\begin{array}{l}\text { Node Elimina- } \\
\text { tion Method }\end{array}$ \\
\hline 1 & Load-1 & 0.882 & 0.871 & 0.882 \\
\hline 2 & Load-2 & 0.823 & 0.821 & 0.823 \\
\hline 3 & Load-3 & 0.856 & 0.825 & 0.856 \\
\hline 4 & Load-4 & 0.850 & 0.848 & 0.850 \\
\hline 5 & Load-5 & 0.813 & 0.811 & 0.813 \\
\hline 6 & Load-6 & 0.814 & 0.821 & 0.814 \\
\hline 7 & Load-7 & 0.810 & 0.789 & 0.810 \\
\hline 8 & Load-8 & 0.833 & 0.822 & 0.833 \\
\hline 9 & Load-9 & 0.855 & 0.845 & 0.855 \\
\hline 10 & $\begin{array}{l}\text { Load- } \\
10\end{array}$ & 0.854 & 0.854 & 0.854 \\
\hline 11 & $\begin{array}{l}\text { Load- } \\
11\end{array}$ & 0.812 & 0.812 & 0.812 \\
\hline 12 & $\begin{array}{l}\text { Load- } \\
12\end{array}$ & 0.836 & 0.826 & 0.836 \\
\hline 13 & $\begin{array}{l}\text { Load- } \\
13\end{array}$ & 0.844 & 0.834 & 0.844 \\
\hline 14 & $\begin{array}{l}\text { Load- } \\
14\end{array}$ & 0.787 & 0.771 & 0.787 \\
\hline 15 & $\begin{array}{l}\text { Load- } \\
15\end{array}$ & 0.761 & 0.742 & 0.761 \\
\hline 16 & $\begin{array}{l}\text { Load- } \\
16\end{array}$ & 0.862 & 0.856 & 0.862 \\
\hline 17 & $\begin{array}{l}\text { Load- } \\
17\end{array}$ & 0.801 & 0.798 & 0.801 \\
\hline
\end{tabular}

\section{Conclusion}

In this paper, the power availability analysis is achieved by a new approach that is using step by step algorithm applying conditional probability along with the concept of Petri nets. The proposed approach is tested with a practical example, IEEE 6, 14 and RTS 96 bus systems. The obtained results show the effectiveness of the complex power systems. This approach consumes less time when compared to the previously done methods. The software used for this analysis is MATLAB software and the proposed methodology is validated by the Monte Carlo simulation and series-parallel equivalence.

\section{Appendix}

The abstraction of conditional probability is discussed by using the practical example given in fig: 1 . In this directed graph genera- 
tors are connected at buses 1,7 and 8 . The loads are connected at buses $2,3,4,5$ and 6 .

The availability of power introduced by generator G1 into the system is given by

$\mathrm{P} 1=\frac{\mu_{\mathrm{G} 1}}{\mu_{\mathrm{G} 1+\lambda_{\mathrm{G} 1}}}$

The incident paths at load 1 are A and B but paths C and D are not incident on bus 2 and the sending end probability of power availability of path a and path $\mathrm{b}$ is $\mathrm{P} 1$

$\mathrm{P} 2=1-\left[\left(1-\mathrm{P} 1 \frac{\mu_{\mathrm{A}}}{\mu_{\mathrm{A}+\lambda_{\mathrm{A}}}}\right)\left(1-\mathrm{P} 1 \frac{\mu_{\mathrm{B}}}{\mu_{\mathrm{B}}+\lambda_{\mathrm{B}}}\right)\right]$

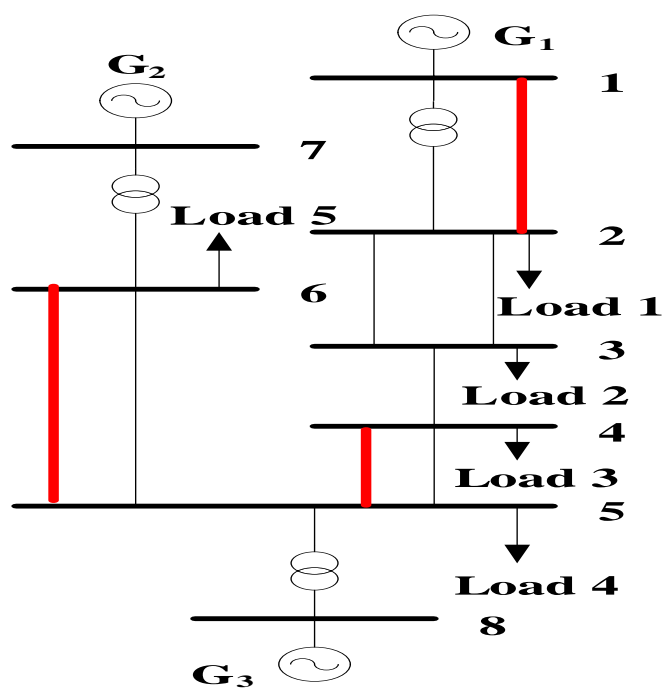

Fig. 1: Interconnected Power System.

The incident paths at load 2 are $\mathrm{C}$ and $\mathrm{D}$ and $\mathrm{E}$ is not incident to bus 2 . The sending end probability of power availability of path $\mathrm{C}$ and path $\mathrm{D}$ is $\mathrm{P} 2$.

$$
\begin{aligned}
& \mathrm{P} 3=1-\left[\left(1-\mathrm{P} 2 \frac{\mu_{\mathrm{C}}}{\mu_{\mathrm{C}}+\lambda_{\mathrm{C}}}\right)\left(1-\mathrm{P} 2 \frac{\mu_{\mathrm{D}}}{\mu_{\mathrm{D}}+\lambda_{\mathrm{D}}}\right)\right] \\
& \mathrm{P} 4=1-\mathrm{P} 3\left(\frac{\mu_{\mathrm{E}}}{\mu_{\mathrm{E}}+\lambda_{\mathrm{E}}}\right) \\
& \mathrm{P} 5=1-\left[\left(1-\mathrm{P} 4 \frac{\mu_{\mathrm{F}}}{\mu_{\mathrm{F}}+\lambda_{\mathrm{F}}}\right)\left(1-\mathrm{P} 4 \frac{\mu_{\mathrm{H}}}{\mu_{\mathrm{H}}+\lambda_{\mathrm{H}}}\right)\left(1-\mathrm{P} 6 \frac{\mu_{\mathrm{I}}}{\mu_{\mathrm{I}}+\lambda_{\mathrm{I}}}\right)\left(1-\mathrm{P} 6 \frac{\mu_{\mathrm{J}}}{\mu_{\mathrm{J}}+\lambda_{\mathrm{J}}}\right)\right]
\end{aligned}
$$

$\mathrm{P} 6=1-\mathrm{P} 7 \frac{\mu_{\mathrm{K}}}{\mu_{\mathrm{K}}+\lambda_{\mathrm{K}}}$

$\mathrm{P} 7=\frac{\mu_{\mathrm{G} 2}}{\mu_{\mathrm{G} 2}+\lambda_{\mathrm{G} 2}}$

$\mathrm{P} 8=1-\mathrm{P} 5 \frac{\mu_{\mathrm{L}}}{\mu_{\mathrm{L}}+\lambda_{\mathrm{L}}}$

Where,

$\mathrm{P} 1, \mathrm{P} 2, \mathrm{P} 3, \mathrm{P} 4, \mathrm{P} 5, \mathrm{P} 6, \mathrm{P} 7$ and $\mathrm{P} 8$ are the probability of power available at respective buses.

$\mu_{A}, \mu_{B}, \mu_{C}, \mu_{D}, \mu_{E}, \mu_{F}, \mu_{H}, \mu_{I}, \mu_{J}$ and $\mu_{K}$ are the repair rates of the respective branches.

$\lambda_{A}, \lambda_{B}, \lambda_{C}, \lambda_{D}, \lambda_{E}, \lambda_{F}, \lambda_{H}, \lambda_{I}, \lambda_{J}$ And $\lambda_{k}$ are the failure rates of the respective branches

By knowing these repair and failure rates of respective branches, so the probability of power availability at all load buses can be obtained.

\section{References}

[1] R. Billinton and R. N. Allan, Reliability Evaluation of Engineering Systems. New York: Plenum, 1992.

[2] P. Fox-Penner, "Smart Power: Climate Change, the Smart Grid, and the Future of Electric Utilities," Washington, DC: Island Press, 2005.

[3] G. T. Heydt, "The next generation of power distribution systems," IEEE Trans. Smart Grid, vol. 1, no. 3, pp. 225-235, 2010. https://doi.org/10.1109/TSG.2010.2080328.

[4] I. S. Bae and J. O. Kim, "Reliability evaluation of customers in a micro grid," IEEE Trans. Power Syst., vol. 23, pp. 1416-1422, 2008. https://doi.org/10.1109/TPWRS.2008.926710.

[5] R. Ramakumar, Engineering Reliability Fundamentals and Applications. Englewood Cliffs, NJ: Prentice-Hall, 1993.

[6] E. Carpaneto, A. Mosso, A. Ponta, and E. Roggero, "Comparison of reliability and availability evaluation techniques for distribution network systems," in Proc. Аппи. Reliability and Maintainability Symp. Jan. 2002, pp. 563-568.

[7] M. Fotuhi-Firuzabad, R. Billinton, T. S. Munian, and B. Vinayagam, "A novel approach to determine minimal tie-sets of complex network," IEEE Trans. Reliab., vol. 53, no. 1, pp. 61-70, 2004. https://doi.org/10.1109/TR.2004.824834

[8] J. Malinowski, "A new efficient algorithm for generating all minimal tie-sets connecting selected nodes in amesh-structured network," IEEE Trans. Reliab., vol. 59, no. 1, pp. 203-211, Mar. 2010. https://doi.org/10.1109/TR.2009.2036712.

[9] T. Bharath Kumar, O. Chandra Sekhar, M. Ramamoorty, S.V. N.L. Lalitha, "Evaluation of power capacity availability at loadbus in a composite power system", IEEE J. Emerg. Sel. Top.Power Electron. 4 (4) (2016) 1324-1331. https://doi.org/10.1109/JESTPE.2016.2615655.

[10] T. Bharath Kumar, O. Chandra Sekhar, M. Ramamoorty, "Composite power system reliability evaluation using modified minimal cut set approach", Alexandria Engineering Journal - Elsevier, 2017 (Accepted- Early access). https://doi.org/10.1016/j.aej.2017.09.008.

[11] T. Murata, "State equation, controllability, and maximal matchings ofPetri nets," IEEE Trans. Autom. Control, vol. 22, p. 412, 1977. https://doi.org/10.1109/TAC.1977.1101509.

[12] Y. Liu and C. Singh, "Reliability evaluation of composite power systems using Markov cut-set method," IEEE Trans. Power Syst., vol. 25, no. 2, pp. 777-785, May 2010 . https://doi.org/10.1109/TPWRS.2009.2033802.

[13] G. S. Hura, K. B. Misra, Ed., "Use of Petri nets for system reliabilityevaluation," in New Trends in Reliability Evaluation. Amsterdam,The Netherlands: Elsevier Science, 1992, pp. 339-368.

[14] G. T. Heydt and T. J. Graf, "Distribution system reliability evaluation using enhanced samples in a Monte Carlo approach," IEEE Trans. Power Syst., vol. 25, no. 4, pp. 2006-2008, Nov. 2010. https://doi.org/10.1109/TPWRS.2010.2045929.

[15] R. Billinton, H. Chen, R. Ghajar, "Time-series models for reliability evaluation of power systems including wind energy" Microelectronics and Reliability, v. 36, 1996, pp. 1253-61. https://doi.org/10.1016/0026-2714(95)00154-9.

[16] A. Jonnavithula, "Composite system reliability evaluation using sequential Monte Carlo simulation," Ph. D. Thesis, University of Saskatchewan, 1997.

[17] A. Sankarakrishnan, R. Billinton, "Sequential Monte Carlo simulation for composite power system reliability analysis with time varying loads," IEEE Transactions on Power Systems, v. 10, no. 3, August 1995, pp. 1540-1545. https://doi.org/10.1109/59.466491.

[18] P. Wang, R. Billinton, "Time sequential distribution system reliability worth analysis considering time varying load and cost models," IEEE Transactions on Power Delivery, v.14, no. 3, Jul 1999, pp. 1046-1051. https://doi.org/10.1109/61.772352.

[19] G. B. Jasmon and K. W. Foong "A method for evaluating all the minimal cut of a graph," IEEE Trans. on reliability, Vol R-25, pp226-233, Oct 1976.

[20] Jose R. Celaya, Alan A. Desrochers, and Robert J. Graves "Modelling and Analysis of Multi-agent Systems using Petri nets"IEEE International Conference on Systems, Man and Cybernetics, 2007.

[21] Nancy G. Leveson AND janice L. STOLZY "Safety Analysis Using Petr Nets, "IEEE Transactions on Software Engineering, Vol SE-13, Mar 1987. 